\title{
Potencial antifúngico de constituintes de óleos essenciais
}

\author{
Antifungal potential of essential oil constituents \\ Potencial antifúngico de los componentes del aceite essencial
}

Recebido: 13/09/2021 | Revisado: 20/09/2021 | Aceito: 25/09/2021 | Publicado: 26/09/2021

Rafaela Vieira Souza
ORCID: https://orcid.org/0000-0002-0037-1237
Universidade Federal de Lavras, Brasil
E-mail: vieiraa.rafaela@ @mail.com
Maria das Graças Cardoso
ORCID: https://orcid.org/0000-0001-8075-1725
Universidade Federal de Lavras, Brasil
E-mail: mcardoso@ ufla.br
Vanuzia Rodrigues Fernandes Ferreira
ORCID: https://orcid.org/0000-0002-6974-0846
Universidade Federal de Lavras, Brasil
E-mail: vanuziarfferreira@gmail.com
Cassia Duarte Oliveira
ORCID: https://orcid.org/0000-0002-2748-2930
Universidade Federal de Lavras, Brasil
E-mail: cassiaduartemg2@ hotmaiil.com
Marcus Vinicius Prado Alves
ORCID: https://orcid.org/0000-0001-5579-8011
Universidade Federal de Lavras, Brasil
E-mail: ordapsevla@yahoo.com.br
Gabriela Aguiar Campolina
ORCID: https://orcid.org/0000-0002-2592-2904
Universidade Federal de Lavras, Brasil
E-mail: gabrielaaguiar25@ hotmail.com
Luís Roberto Batista
ORCID: https://orcid.org/0000-0001-8482-1161
Universidade Federal de Lavras, Brasil
E-mail: luisrb@ufla.br

\section{Resumo}

Os produtos naturais são importantes fontes para o desenvolvimento de novos agentes medicinais e, devido ao potencial biológico e farmacológico desses compostos, torna-se necessário realizar estudos que viabilizem sua aplicação. Objetivou-se neste trabalho avaliar o potencial antifúngico de determinados constituintes de óleos essenciais. A avaliação do efeito inibitório dos compostos p-cimeno, eugenol, carvacrol, citral, trans-cariofileno e trans-farnesol foi testada sobre os fungos Aspergillus carbonarius, Aspergillus flavus, Aspergillus ochraceus e Aspergillus niger, empregando-se a metodologia de difusão em disco. Avaliou-se o efeito dos compostos eugenol, carvacrol e citral sobre o crescimento micelial dos fungos A. carbonarius e A. niger em diferentes temperaturas. A análise da atividade inibitória dos fungos revelou que os compostos eugenol, carvacrol e citral mostraram maior capacidade em inibir o crescimento dos micro-organismos avaliados. Esses constituintes também influenciaram o crescimento micelial dos fungos A. niger e A. carbonarius em diferentes temperaturas, sendo as temperaturas de $20{ }^{\circ} \mathrm{C}$ e $25{ }^{\circ} \mathrm{C}$ mais propícias para o desenvolvimento dos fungos. Os resultados encontrados mostraram-se promissores na busca por compostos bioativos. Estudos envolvendo esses constituintes podem ser relevantes em outras atividades, bem como em associação com os compostos sintéticos já empregados a fim de diminuir a toxicidade e resistência dos mesmos e avaliar o efeito sinérgico entre eles.

Palavras-chave: Constituintes; Óleos essenciais; Fungos.

\begin{abstract}
Natural products are important sources of discovery of new medicinal agents and, due to the biological and pharmacological potential of these compounds, it is necessary to carry out studies to enable their application. The objective of this work was to evaluate the antifungal potential of certain constituents of essential oils. The evaluation of the inhibitory effect of the compounds p-cimene, eugenol, carvacrol, citral, trans-caryophyllene and trans-farnesol was tested on the fungi Aspergillus carbonarius, Aspergillus flavus, Aspergillus ochraceus and Aspergillus niger, using the disk diffusion methodology. The effect of eugenol, carvacrol and citral compounds on the mycelial growth of A. carbonarius and A. niger fungi at different temperatures was evaluated. The analysis of the inhibitory activity of the fungi revealed that the compounds eugenol, carvacrol and citral showed greater capacity to inhibit the growth of
\end{abstract}


the evaluated microorganisms. These constituents also influenced the mycelial growth of the fungi A. niger and A. carbonarius at different temperatures, with temperatures of $20^{\circ} \mathrm{C}$ and $25^{\circ} \mathrm{C}$ being more favorable for the development of the fungi. The results found proved to be promising in the search for bioactive compounds. Studies involving these constituents may be relevant in other activities, as well as in association with synthetic compounds already used in order to reduce their toxicity and resistance and assess the synergistic effect between them.

Keywords: Constituents; Essencial oils; Fungi.

\section{Resumen}

Los productos naturales son fuentes importantes de descubrimiento de nuevos agentes medicinales y, debido al potencial biológico y farmacológico de estos compuestos, es necesario realizar estudios que permitan su aplicación. El objetivo de este trabajo fue evaluar el potencial antifúngico de ciertos constituyentes de los aceites esenciales. La evaluación del efecto inhibidor de los compuestos p-cimeno, eugenol, carvacrol, citral, trans-cariofileno y transfarnesol se probó en los hongos Aspergillus carbonarius, Aspergillus flavus, Aspergillus ochraceus y Aspergillus niger, utilizando la metodología de difusión en disco. Se evaluó el efecto de los compuestos eugenol, carvacrol y citral sobre el crecimiento micelial de los hongos A. carbonarius y A. niger a diferentes temperaturas. El análisis de la actividad inhibidora de los hongos reveló que los compuestos eugenol, carvacrol y citral mostraron mayor capacidad para inhibir el crecimiento de los microorganismos evaluados. Estos constituyentes también influyeron en el crecimiento micelial de los hongos A. niger y A. carbonarius a diferentes temperaturas, siendo las temperaturas de 20 ${ }^{\circ} \mathrm{C}$ y $25{ }^{\circ} \mathrm{C}$ más favorables para el desarrollo de los hongos. Los resultados encontrados demostraron ser prometedores en la búsqueda de compuestos bioactivos. Pueden ser relevantes los estudios que involucren a estos constituyentes en otras actividades, así como en asociación con compuestos sintéticos ya utilizados para reducir su toxicidad y resistencia y evaluar el efecto sinérgico entre ellos.

Palabras clave: Constituyentes; Aceites esenciales; Hongos.

\section{Introdução}

Um dos maiores problemas a nível mundial é a contaminação de alimentos por espécies fúngicas, sendo uma grande ameaça à saúde de humanos e animais, causando perdas econômicas significativas em países em desenvolvimento e desenvolvidos (Davies et al., 2021).

Tendo em vista o potencial de prejuízos agronômicos causados pelos fungos fitopatogênicos, não há dúvidas da necessidade de se fazer o controle populacional dos mesmos. Entretanto, o uso intensivo e indiscriminado do controle químico, incluindo agentes de alta toxicidade, para combate de pragas, tem afetado negativamente o meio ambiente e o ser humano em função do acúmulo dos resíduos, além da contaminação de espécies não alvo e a constante aquisição de resistência, Oliveira et al., 2020; Ketzer et al., 2020).

Algumas espécies fúngicas são produtoras de micotoxinas como Aspergillus flavus, Aspergillus nomius, Aspergillus parasiticus, enquanto outras são produtoras de ocratoxinas, como Aspergillus carbonarius, Aspergillus niger, Aspergillus ochraceus e Aspergillus westerdijkiae. Esses compostos geram preocupação mundial por serem carcinogênicos. O Aspergillus é encontrado na natureza e pode deteriorar alimentos, como por exemplo carnes (Aspergillus ochraceus), uvas (Aspergillus carbonarius, ) e nozes e cereais (Aspergillus niger e Aspergillus flavus) (Lemos et al., 2020).

Nesse contexto, a busca por defensivos naturais compõe uma fonte alternativa sustentável de moléculas ativas de baixa toxicidade com menores danos ao meio ambiente e à saúde humana. Os metabolitos secundários produzidos pelas plantas possuem maior diversidade estrutural, dificultando a aquisição de resistência, além de menor persistência no ambiente em função dos microrganismos capazes de metabolizar esses compostos orgânicos (de Oliveira et al., 2020; Ketzer et al., 2020).

Assim, o objetivo desse estudo é verificar o potencial antifúngico de determinados constituintes de óleos essenciais, como o p-cimeno, eugenol, carvacrol, citral, trans-cariofileno e trans-farnesol, na inibição do crescimento dos fungos Aspergillus carbonarius, Aspergillus flavus, Aspergillus ochraceus e Aspergillus niger, com o intuito de controlar a deterioração de alimentos e evitar que sejam produzidas toxinas fúngicas. 


\section{Metodologia}

O trabalho foi desenvolvido nos Laboratórios de Química Orgânica - Óleos Essenciais, do Departamento de Química (DQI), no Laboratório de Micotoxinas e Micologia de Alimentos, do Departamento de Ciência dos Alimentos (DCA) da Universidade Federal de Lavras, Minas Gerais - Brasil.

\subsection{Atividade antifúngica}

Foram pesquisadas quatro espécies de fungos filamentosos: Aspergillus carbonarius (CCDCA 10507), Aspergillus flavus (CCDCA 10508), Aspergillus ochraceus (CCDCA 10506) e Aspergillus niger (CCDCA 10535). Todas as espécies foram adquiridas da Coleção de Cultura de Micro-organismos do DCA-UFLA.

Escolheu-se um constituinte de cada classe de terpenos e fenilpropanoides para analisar a atividade antifúngica sobre os fungos filamentosos. Os compostos escolhidos foram o p-cimeno, eugenol, carvacrol, citral, trans-cariofileno e transfarnesol, obtidos pela Acros e Sigma Chemical, pertencentes às classes monoterpeno, fenilpropanoide, monoterpeno com características fenólica, monoterpeno oxigenado, sesquiterpeno e sesquiterpeno oxigenado, respectivamente (Figura 1).<smiles>Cc1ccc(C(C)C)cc1</smiles>

-cimeno<smiles>CC(C)=CCC/C(C)=C/C=O</smiles>

Citral

Figura 1. Estrutura química dos compostos testados na atividade antifúngica.

Eugenol<smiles>C=CCc1ccc(O)c(OC)c1</smiles><smiles>CC1=CCCCC2CC(C)(C)C2CC1</smiles>

trans-cariofileno<smiles>Cc1ccc(C)c(O)c1</smiles>

Carvacrol

Fonte: Autores (2018).<smiles>CC(C)=CCCC=CCCC(C)=CCO</smiles>

trans-farnesol
$\mathrm{OH}$

\subsection{Avaliação do efeito inibitório de constituntes de óleos essenciais sobre fungos do gênero Aspergillus}

A análise do efeito inibitório dos constituintes de óleos essenciais sobre fungos filamentosos foi realizada utilizandose o teste de difusão em disco aceito pelo Food and Drug Administration (FDA) e estabelecido pelo National Committe for Clinical Laboratory Standards (NCCLS) (Brasil, 2017). Para isso, utilizou-se um inóculo na concentração de $10^{6}$ esporos $\mathrm{mL}^{-1}$, com contagem em Câmara de Newbauer.

Após a contagem, transferiu-se o inóculo para a placa contendo meio de Agar Extract Malt (MEA), por meio da técnica de espalhamento em superfície. Foram adicionados discos de papel-filtro (5mm de diâmetro) sobre o meio de cultura e, em seguida, foram pipetados nos discos $10 \mu \mathrm{L}$ dos padrões de óleos essenciais diluídos em dimetilsulfóxido (DMSO) nas concentrações de 500; 250; 125; 62,5; 31,25; 15,62; 7,81 e 3,90 $\mu \mathrm{L} \mathrm{mL}^{-1}$. Empregou-se DMSO como controle relativo e o fungicida sintético fluodioxonil $\left(2 \mu \mathrm{L} \mathrm{mL}^{-1}\right)$ como padrão de comparação. As placas foram incubadas em Demanda Bioquímica 
de Oxigênio (BOD) a $25{ }^{\circ} \mathrm{C}$ durante 72 horas e, logo após, foram realizadas medições diametralmente opostas dos halos de inibição formados (Andrade et al., 2015).

O teste foi realizado em triplicata e definiu-se a concentração mínima inibitória (CMI) como a menor concentração da amostra em que foi perceptível a presença do halo de inibição.

\subsection{Efeito dos compostos sobre o crescimento micelial dos fungos}

A análise do crescimento micelial dos fungos foi realizada de acordo com Singh et al. (2008), com modificações. Como realizado para a avaliação do efeito inibitório, utilizou-se um inóculo na concentração de $10^{6}$ esporos $\mathrm{mL}^{-1}$, com contagem em câmara de Newbauer. O plaqueamento foi realizado adicionando-se $20 \mathrm{~mL}$ de meio Czapeck Yeast Agar (CYA) com os compostos diluídos em DMSO e, em seguida, foram adicionados $10 \mu \mathrm{L}$ da suspensão de esporos dos fungos $A$. carbonarius e A. niger no centro da placa.

Para fins de comparação, $10 \mu \mathrm{L}$ da suspensão de esporos foram adicionados à placa contendo apenas o meio, sem a amostra. $\mathrm{O}$ experimento foi realizado em triplicata e as placas foram vedadas e incubadas a BOD a 15,20 e $25{ }^{\circ} \mathrm{C}$, no escuro por 10 dias, sendo realizadas medições diametralmente opostas dos halos formados no $10^{\circ}$ dia.

\subsection{Avaliação dos dados e análise estatística}

O delineamento experimental utilizado foi o inteiramente casualizado (DIC) com um esquema fatorial de $5 \times 3$ (concentrações x tempeturas), com três repetições. O programa estatístico utilizado foi o SISVAR (Ferreira, 2011).

Os dados foram submetidos à análise de variância para a verificação dos tratamentos com os óleos essenciais sobre os resultados da redução do crescimento micelial e as médias foram comparadas pelo teste de Tukey, ao nível de 5\% de probabilidade.

\section{Resultados e Discussão}

\subsection{Efeito inibitório dos constituintes de óleos essenciais sobre fungos do gênero Aspergillus}

Os valores referentes às concentrações mínimas inibitórias (CMIs) dos compostos p-cimeno, eugenol, carvacrol, citral, trans-cariofileno e trans-farnesol sobre os fungos A. carbonarius, A. flavus, A. ochraceus e A. niger, utilizando-se a metodologia de difusão em disco, estão descritos na Tabela 1.

Tabela 1. Concentração mínima inibitória dos compostos p-cimeno, eugenol, carvacrol, citral, trans-cariofileno e transfarnesol sobre fungos do gênero Aspergillus.

\begin{tabular}{ccccccccc}
\hline & \multicolumn{7}{c}{ CMI $\left(\mu \mathrm{LL}^{-1}\right)$} \\
\cline { 2 - 8 } Fungo & p-cim & Eug & Car & Cit & t-car & t-far & DMSO & Flu \\
\hline $\begin{array}{c}\text { A. } \\
\text { carbonarius }\end{array}$ & 125 & 15,62 & 15,62 & 31,25 & 250 & 31,25 & NI & 2 \\
$\begin{array}{c}\text { A. flavus } \\
\text { A. }\end{array}$ & 125 & 15,62 & 15,62 & 31,25 & 250 & 125 & NI & 2 \\
ochraceus & 125 & 7,81 & 7,81 & 15,62 & 250 & 31,25 & NI & 2 \\
A. niger & 125 & 7,81 & 7,81 & 7,81 & 250 & 125 & NI & 2 \\
\hline
\end{tabular}

Legenda: p-cim - p-cimeno; Eug - Eugenol; Car - Carvacrol; Cit - Citral; t-car - trans-cariofileno; t-far - trans-farnesol; DMSO dimetilsulfóxido; NI - Não inibiu; Flu. - Fluodioxonil. Fonte: Autores (2018). 
A atividade antifúngica dos derivados terpênicos e fenilpropanoides que constituem os óleos essenciais dependem de sua estrutura química. Os resultados encontrados evidenciam que os compostos eugenol e carvacrol apresentam maior potencial de inibição sobre os fungos analisados. Além disso, os fungos A. ochraceus e A. niger mostraram-se mais sensíveis frente aos constituintes avaliados.

Vieira e colaboradores (2014) apontam que o caráter lipofílico do esqueleto carbônico, bem como o caráter hidrofílico de seus grupos funcionais, são aspectos relevantes na determinação do potencial antimicrobiano de constituintes de óleos essenciais. Dessa forma, a atividade antimicrobiana segue a seguinte ordem: fenóis > aldeídos > cetonas > álcoois > éteres > hidrocarbonetos.

Essa relação entre a atividade antimicrobiana e o grupo funcional presente no composto vai de encontro com os resultados encontrados neste trabalho. Assim, o eugenol, um composto fenólico e o carvacrol, um monoterpeno com características fenólicas, apresentaram melhor eficácia na inibição dos micro-organismos, mostrando atividade nas menores concentrações testadas. Ainda nessa mesma linha de raciocínio, tem-se o citral, que apresenta o grupo funcional aldeído em sua estrutura química, e portanto, apresenta maior atividade antifúngica que o trans-farnesol, que é um álcool. Por fim, os compostos p-cimeno e trans-cariofileno apresentaram menor capacidade em inibir o crescimento dos fungos, uma vez que são hidrocarbonetos. Contudo, infere-se que compostos com cadeia carbônica menor apresentem maior facilidade em atravessar a camada lipídica dos fungos. Assim, a maior eficácia do $p$-cimeno, quando comparado ao trans-cariofileno, pode ser devido ao fato de o primeiro ser monoterpeno (10 C), ao passo que o segundo é sesquiterpeno (15 C).

Ao analisar a composição celular dos fungos, pelo menos seis mecanismos antifúngicos diferentes podem ser sugeridos. Esses mecanismos baseiam-se na inibição da formação da parede celular, ruptura da membrana celular, disfunção da mitocôndria dos fungos, inibição da divisão celular, inibição da síntese de DNA/RNA e de proteínas e inibição da bomba de prótons (Lagrouh, Dakka \& Bakri, 2017).

Como a parede celular dos fungos consiste principalmente em $\beta$-glucanos e quitina, e uma vez que a síntese desses compostos é inibida, rompe-se a integridade da parede celular. Em relação à membrana celular, o ergosterol é um esterol essencial para o desempenho da membrana e quando associados a drogas antifúngicas ou a inibidores de sua biossíntese, irá ocorrer perturbação na integridade da membrana celular. Levando em consideração a função das mitocôndrias, se o transporte mitocondrial de elétrons for inibido, acarretará redução no potencial de membrana. Esse bloqueio pode ocorrer por meio da inibição das bombas de prótons na cadeia respiratória, seguida da redução na produção de ATP e subsequente morte celular. A inibição da divisão celular pode ocorrer por intermédio da inibição da polimerização de microtúbulos e, por conseguinte, bloqueio da formação do fuso mitótico. Em referência à inibição da síntese de DNA/RNA e proteínas, essa ocorre quando o agente antifúngico penetra na célula e envolve-se com o RNA, induzindo as inibições na síntese de RNA e na transcrição de DNA, sendo essas inibições alvos antifúngicos conhecidos. Por fim, o bombeamento de agentes antifúngicos do meio intracelular para o meio extracelular, isto é, seu efluxo ativo, ocasiona resistência fúngica a determinados antifúngicos e, dessa forma, a inibição da bomba de efluxo gera redução da resistência dos fármacos (Lagrouh, Dakka \& Bakri, 2017); Sun; Deng; Yan, 2014; Zore et al., 2011).

A membrana plasmática desempenha uma função essencial, uma vez que está relacionada à manutenção de um ambiente homeostático, troca de substâncias, transferência de energia e informação nas células fúngicas, a fim de mantê-las vivas e saudáveis. Além disso, as mitocôndrias também são de fundamental importância, visto que são responsáveis pela produção de energia, homeostase de pH, equilíbrio redox, tampão de cálcio, regulação do nível de segundos mensageiros e regulação da apoptose (Tian et al., 2012).

Abbaszadeh e colaboradores (2014) salientaram que o mecanismo de ação dos compostos fenólicos ainda não é muito bem elucidado, embora danos na membrana e na parede celular bem como deformações morfológicas com deterioração dos 
conídios e hifas sejam abordados. Oliveira e colaboradores (2016) avaliaram o potencial antifúngico do óleo essencial de Ocimum gratissimum, que possui o eugenol como componente majoritário $(51,84 \%)$. Os autores observaram que o óleo essencial (OE) promoveu alteração na permeabilidade da membrana celular, sendo esse um dos mecanismos de ação mais prováveis dos OE's. Além do mais, relatam que o potencial antifúngico elevado dos compostos fenólicos eugenol e carvacrol pode ser explicado devido à acidez do grupo hidroxila, capaz de formar ligação de hidrogênio com o centro ativo das enzimas dos micro-organismos, prevenindo a ação enzimática. Outro aspecto relacionado com a atividade antifúngica é destacado por Pisoschi e colaboradores (2017) em relação à influência da estrutura fenólica na atividade antimicrobiana, dado que compostos que são capazes de promover a deslocalização dos pares de elétrons podem atuar como trocadores de prótons, diminuindo o gradiente de pH na membrana citoplasmática. Isso causa a decadência da força motriz dos prótons, redução da síntese de ATP e, subsequentemente, morte celular.

Considerando a natureza lipofílica desses compostos presentes em diversos óleos essenciais, pode-se inferir que eles atuam entre as cadeias de ácido graxo da bicamada lipídica, interrompendo sua fluidez e permeabilidade. Para Wang e colaboradores (2015) e Marchese e colaboradores (2017), esses compostos podem se acumular na membrana celular, desintegrando-a e tornando-a altamente permeável a íons que possam ser responsáveis pela atividade antifúngica. De fato, manter a homeostasia dos íons é fundamental para manter o estado de energia da célula, bem como processos acoplados à membrana e dependentes de energia, como o transporte de soluto, regulação do metabolismo, controle da pressão e mobilidade.

Os monoterpenos que apresentam o grupo funcional aldólico em sua estrutura são conhecidos por possuírem atividade antimicrobiana. Dessa maneira, tem sido proposto que um grupo aldeído conjugado com uma dupla ligação carbono-carbono $(\mathrm{C}=\mathrm{C})$ forma um arranjo altamente eletronegativo e infere-se que um aumento na eletronegatividade resulta em um aumento no potencial antimicrobiano. Esses compostos eletronegativos podem interferir no processo biológico envolvendo a transferência de elétrons e, então, inibir o crescimento do micro-organismo (Bhatti et al., 2014).

Ressalta-se a contribuição dos autores Tao, Ouyang e Jia (2014), posto que eles investigaram a atividade antifúngica, juntamente com o mecanismo de ação do composto citral sobre um dos principais patógenos de pós-colheita do gênero Citrus, Penicillium italicum. Nessa pesquisa, salientam que o citral alterou a morfologia das hifas de $P$. italicum, causando perda do citoplasma e distorção do micélio. Além disso, o composto agiu de modo dose dependente com a membrana, uma vez que o aumento na concentração de citral impactou em aumento na permeabilidade da membrana, evidenciado pela liberação de constituintes celulares, $\mathrm{pH}$ extracelular e vazamento de íons. Destacaram também que o citral pode induzir a uma diminuição dos teores de lipídios e de ergosterol presentes na membrana de P. italicum, indicando a ruptura da integridade da mesma. Infere-se com esses resultados que a atividade antifúngica do citral sobre $P$. italicum pode ser atribuída à interrupção da integridade da membrana celular, bem como ao aumento da permeabilidade da mesma.

De modo similar, Leite e colaboradores (2014) analisaram a atividade antifúngica e o possível mecanismo de ação do citral sobre Candida albicans. Os autores notaram que o composto não atua na inibição da síntese da parede celular, mas, sim, na membrana celular, afetando sua estrutura, bloqueando sua síntese e induzindo à morte celular, pois inibe a germinação de esporos, a proliferação e a respiração celular.

O potencial antifúngico observado para o trans-farnesol pode ser atribuído à sua natureza hidrofóbica, visto que esse apresenta uma cadeia com 15 átomos de carbono e uma pequena parte hidrofílica, devido à presença da hidroxila. Assim, possui alta afinidade pela membrana da célula fúngica, sendo capaz de acumular-se na mesma, causando expansão e comprometendo sua integridade devido à liberação do material intracelular (D'amato et al., 2018). Bhatti e colaboradores (2014) acreditam que a porção alcoólica presente na molécula seja fator determinante para sua atividade antifúngica, sendo prioritária em relação à estrutura cíclica ou acíclica do composto. 
Apesar da atividade antifúngica indicada pelo trans-farnesol, ela não é tão expressiva quanto aquela encontrada para os compostos carvacrol e eugenol. Embora o trans-farnesol tenha um grupamento hidroxil, ele não apresenta um sistema de deslocalização de elétrons, e por conseguinte, o grupo hidroxil não possui tendência em liberar o próton.

Os monoterpenos não representam um grupo de constituintes com alta atividade antifúngica e diversos estudos demonstram que são ineficientes, quando testados sozinhos (Gomes et al., 2014; Hyldgaard; Mygind \&Meyer, 2012; Kordali et al., 2008; Marchese et al., 2017). O p-cimeno, precursor do carvacrol, atua como uma "impureza substitutiva" na membrana, uma vez que substitui as moléculas lipídicas, causando variações na temperatura de transição e nos valores de entalpia. Em virtude da afinidade do p-cimeno com a membrana, esse perturba a mesma parcialmente, causando expansão e, consequentemente, afetando o potencial de membrana de células intactas. Devido ao fato de ser um monoterpeno com um anel benzênico sem a presença de nenhum grupo funcional em sua cadeia carbônica, o $p$-cimeno não afeta a permeabilidade da membrana, mas altera outros parâmetros físico-químicos, como temperatura e entalpia (Cristani et al., 2007; Hyldgaard; Mygind; Meyer, 2012).

Ultee, Bennik e Moezelaar (2002) também comentaram que, na presença do $p$-cimeno, o potencial de membrana diminui principalmente pelo extravasamento de outros íons que não sejam o $\mathrm{H}^{+}$, por exemplo $\mathrm{K}^{+}$, porque somente um pequeno efeito no pH foi observado. Essa baixa variação no pH pode explicar o motivo pelo qual a síntese de ATP não foi afetada pelo $p$-cimeno. Os autores ressaltam que tanto o carvacrol quanto o $p$-cimeno possuem um efeito na integridade da membrana; porém, a desestabilização da membrana não explica a alta atividade antimicrobiana do carvacrol quando comparada com o $p$ cimeno. Assim, inferem que outro fator esteja envolvido, sendo, portanto, a presença da hidroxila na molécula de carvacrol. Constataram que o $p$-cimeno atua sinergisticamente com o carvacrol causando a expansão da membrana; entretanto, a atividade antimicrobiana do carvacrol é causada pela diminuição do pH como resultado de um grupo hidroxil e um sistema de elétrons deslocalizados.

O sesquiterpeno bicíclico trans-cariofileno foi o composto que apresentou menor eficácia no combate aos fungos estudados. Pode-se inferir que esse resultado seja devido à ausência de hidroxila em sua estrutura bem como à deficiência de duplas conjugadas. Além disso, por apresentar uma estrutura bicíclica com 15 átomos de carbono, espera-se que seja mais dificultoso interagir com a membrana celular e romper sua integridade.

Diversos trabalhos citam as associações entre a atividade antifúngica e a inibição da biossíntese do ergosterol, bem como a ruptura da integridade da membrana. De modo similar, outros autores argumentam que o potencial antifúngico dos óleos essenciais e seus componentes esteja relacionado aos danos causados na membrana citoplasmática e subsequente vazamento de compostos intracelulares (DNA), bem como a interrupção do sistema de endomembrana de células fúngicas, isto é, inibição da síntese do ergosterol e das atividades da malato desidrogenase, ATPase mitocondrial, e succinato desidrogenase estão relacionadas ao potencial antifúngico (Ahmad et al., 2011; Hu et al., 2017; Silva et al., 2011b). Dessa forma, é complicado prever o quão susceptível determinado micro-organismo é perante certo composto, assim como seu modo de ação e sua interação com o ambiente circundante.

\subsection{Efeito dos compostos eugenol, carvacrol e citral sobre o crescimento micelial dos fungos Aspergillus carbonarius e Aspergillus niger em diferentes temperaturas}

Diante dos resultados obtidos no teste anterior, decidiu-se avaliar o efeito dos compostos eugenol, carvacrol e citral sobre o crescimento micelial dos fungos Aspergillus carbonarius e Aspergillus niger em diferentes temperaturas. Os valores do diâmetro médio do crescimento micelial do fungos A. carbonarius sobre os compostos analisados estão representados nas Tabelas 2,3 e 4. 
Tabela 2. Diâmetro médio do crescimento micelial do fungo Aspergillus carbonarius sobre o composto carvacrol.

\begin{tabular}{ccccccc}
\hline \multirow{2}{*}{$\begin{array}{c}\text { Concentração } \\
\left(\mu \mathrm{L} \mathrm{mL}{ }^{-1}\right)\end{array}$} & \multicolumn{3}{c}{ Temperatura $\left({ }^{\circ} \mathrm{C}\right)$} & \multicolumn{3}{c}{ Inibição micelial $(\%)$} \\
\cline { 2 - 7 } & 15 & 20 & 25 & 15 & 20 & 25 \\
\hline 1,95 & $3,417 \mathrm{Ab}$ & $5,633 \mathrm{Aa}$ & $6,183 \mathrm{Ba}$ & 0,000 & 17,368 & 27,259 \\
3,91 & $1,500 \mathrm{Bb}$ & $5,133 \mathrm{Aa}$ & $5,183 \mathrm{Ba}$ & 14,286 & 24,703 & 39,023 \\
7,81 & $0,000 \mathrm{Cb}$ & $1,900 \mathrm{Ba}$ & $0,000 \mathrm{Cb}$ & 100,000 & 72,128 & 100,000 \\
15,62 & $0,000 \mathrm{Ca}$ & $0,000 \mathrm{Ca}$ & $0,000 \mathrm{Ca}$ & 100,000 & 100,000 & 100,000 \\
Testemunha & $1,750 \mathrm{Bc}$ & $6,817 \mathrm{Ab}$ & $8,500 \mathrm{Aa}$ & 0,000 & 0,000 & 0,000 \\
\hline
\end{tabular}

Legenda: As médias seguidas pela mesma letra minúscula nas colunas e pela mesma letra maiúscula nas linhas não diferem entre si pelo Teste de Tukey, ao nível de 5\% de probabilidade. Fonte: Autores (2018).

Tabela 3. Diâmetro médio do crescimento micelial do fungo Aspergillus carbonarius sobre o composto citral.

\begin{tabular}{ccccccc}
\hline $\begin{array}{c}\text { Concentração } \\
\left(\mu \mathrm{L} \mathrm{mL} \mathrm{mL}^{-1}\right)\end{array}$ & \multicolumn{3}{c}{ Temperatura $\left({ }^{\circ} \mathrm{C}\right)$} & \multicolumn{3}{c}{ Inibição micelial (\%) } \\
\cline { 2 - 7 } & 15 & 20 & 25 & 15 & 20 & 25 \\
\hline 3,91 & $0,000 \mathrm{Bc}$ & $3,917 \mathrm{Bb}$ & $8,667 \mathrm{Aa}$ & 100,000 & 42,541 & 0,000 \\
7,81 & $0,000 \mathrm{Bb}$ & $0,000 \mathrm{Cb}$ & $4,133 \mathrm{Ba}$ & 100,000 & 100,000 & 51,376 \\
15,62 & $0,000 \mathrm{Ba}$ & $0,000 \mathrm{Ca}$ & $0,000 \mathrm{Ca}$ & 100,000 & 100,000 & 100,000 \\
31,25 & $0,000 \mathrm{Ba}$ & $0,000 \mathrm{Ca}$ & $0,000 \mathrm{Ca}$ & 100,000 & 100,000 & 100,000 \\
Testemunha & $1,750 \mathrm{Ac}$ & $6,817 \mathrm{Ab}$ & $8,500 \mathrm{Aa}$ & 0,000 & 0,000 & 0,000 \\
\hline
\end{tabular}

Legenda: As médias seguidas pela mesma letra minúscula nas colunas e pela mesma letra maiúscula nas linhas não diferem entre si pelo Teste de Tukey, ao nível de 5\% de probabilidade. Fonte: Autores (2018).

Tabela 4. Diâmetro médio do crescimento micelial do fungo Aspergillus carbonarius sobre o composto eugenol.

\begin{tabular}{ccccccc}
\hline $\begin{array}{c}\text { Concentração } \\
\left.(\mu \mathrm{L} \mathrm{mL})^{-1}\right)\end{array}$ & 15 & 20 & 25 & 15 & 20 & 25 \\
\cline { 2 - 7 } & $2,100 \mathrm{Ac}$ & $6,583 \mathrm{Ab}$ & $9,000 \mathrm{Aa}$ & 0,000 & 3,433 & 0,000 \\
3,95 & $1,067 \mathrm{Ab}$ & $6,400 \mathrm{Aa}$ & $6,483 \mathrm{Ba}$ & 39,029 & 6,117 & 23,729 \\
7,91 & $0,000 \mathrm{Bc}$ & $5,683 \mathrm{Aa}$ & $2,583 \mathrm{Cb}$ & 100,000 & 16,635 & 69,612 \\
15,62 & $0,000 \mathrm{Ba}$ & $0,000 \mathrm{Ba}$ & $0,000 \mathrm{Da}$ & 100,000 & 100,000 & 100,000 \\
Testemunha & $1,750 \mathrm{Ac}$ & $6,817 \mathrm{Ab}$ & $8,500 \mathrm{Aa}$ & 0,000 & 0,000 & 0,000 \\
\hline
\end{tabular}

Legenda: As médias seguidas pela mesma letra minúscula nas colunas e pela mesma letra maiúscula nas linhas não diferem entre si pelo Teste de Tukey, ao nível de 5\% de probabilidade. Fonte: Autores (2018).

Os compostos carvacrol e citral apresentaram inibição total do crescimento micelial de A. carbonarius a partir das concentrações de 7,81 e 15,625 $\mu \mathrm{L} \mathrm{mL}^{-1}$, respectivamente, na temperatura de $25{ }^{\circ} \mathrm{C}$, uma concentração abaixo daquela realizada no teste preliminar para CMI. O eugenol respondeu como esperado, apresentando inibição total do crescimento micelial a partir da concentração de 15,62 $\mu \mathrm{L} \mathrm{mL}^{-1}$. Além disso, constatou-se diferença significativa em relação ao crescimento micelial nas temperaturas de 25,20 e $15{ }^{\circ} \mathrm{C}$, sendo a temperatura de $15{ }^{\circ} \mathrm{C}$ menos eficaz para o crescimento do fungo e as temperaturas de $20{ }^{\circ} \mathrm{C}$ e $25{ }^{\circ} \mathrm{C}$ as mais propícias para o seu desenvolvimento. Também foi possível observar que o composto carvacrol, em sua menor concentração $\left(1,95 \mu \mathrm{L} \mathrm{mL}^{-1}\right)$, estimulou o crescimento do fungo A. carbonarius na temperatura de 15 ${ }^{\circ} \mathrm{C}$, diferindo-se estatisticamente do valor do diâmetro encontrado para a testemunha, o qual se esperava ser o maior em relação ao crescimento micelial. As Figuras 2, 3 e 4 mostram a inibição do crescimento micelial do fungo A. carbonarius pelos compostos carvacrol, citral e eugenol, respectivamente, nas concentrações que variam de 1,95 a $31,25 \mu \mathrm{L} \mathrm{mL}^{-1}$. 
Figura 2. Inibição do crescimento micelial de Aspergillus carbonarius pelo composto carvacrol, nas temperaturas de 25,20 e $15^{\circ} \mathrm{C}$.

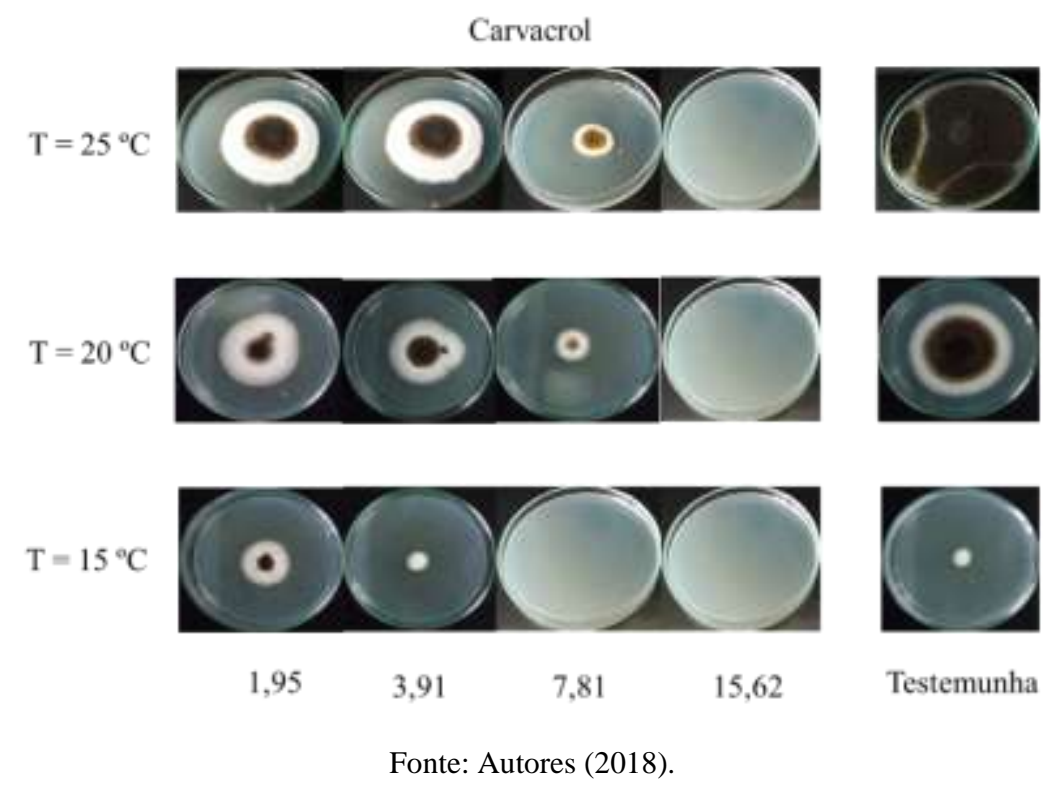

Figura 3. Inibição do crescimento micelial de Aspergillus carbonarius pelo composto citral, nas temperaturas de 25,20 e 15 ${ }^{\circ} \mathrm{C}$.

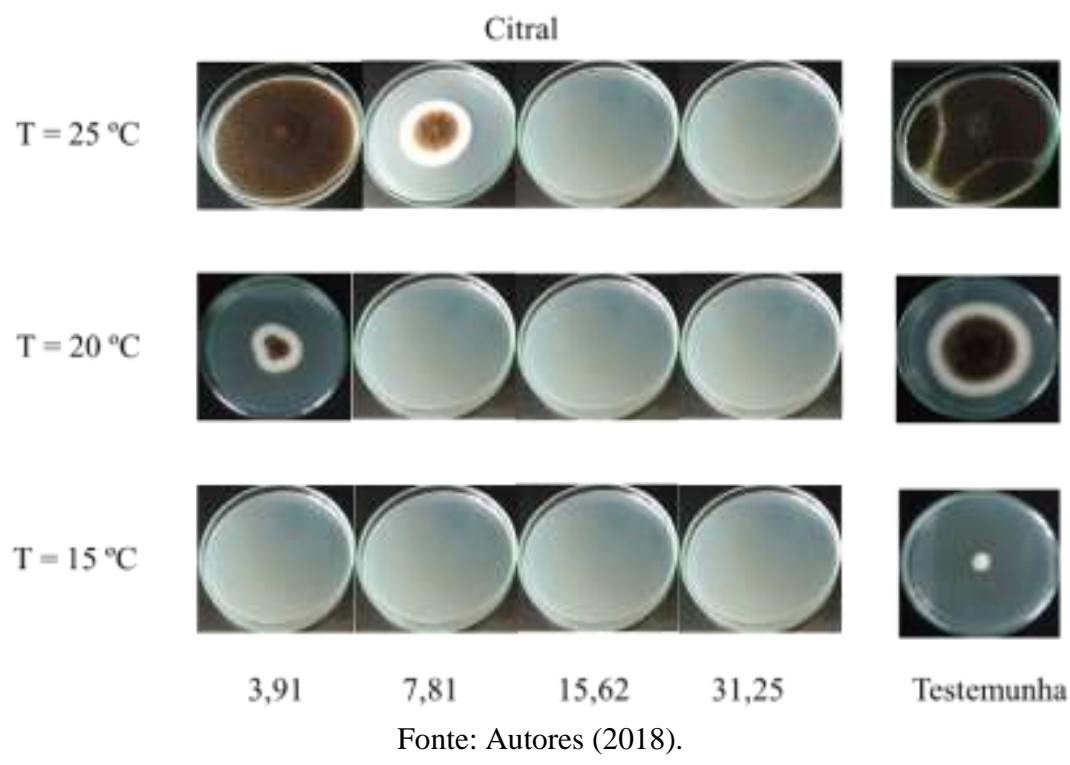


Figura 4. Inibição do crescimento micelial de Aspergillus carbonarius pelo composto eugenol, nas temperaturas de 25,20 e 15 ${ }^{\circ} \mathrm{C}$.

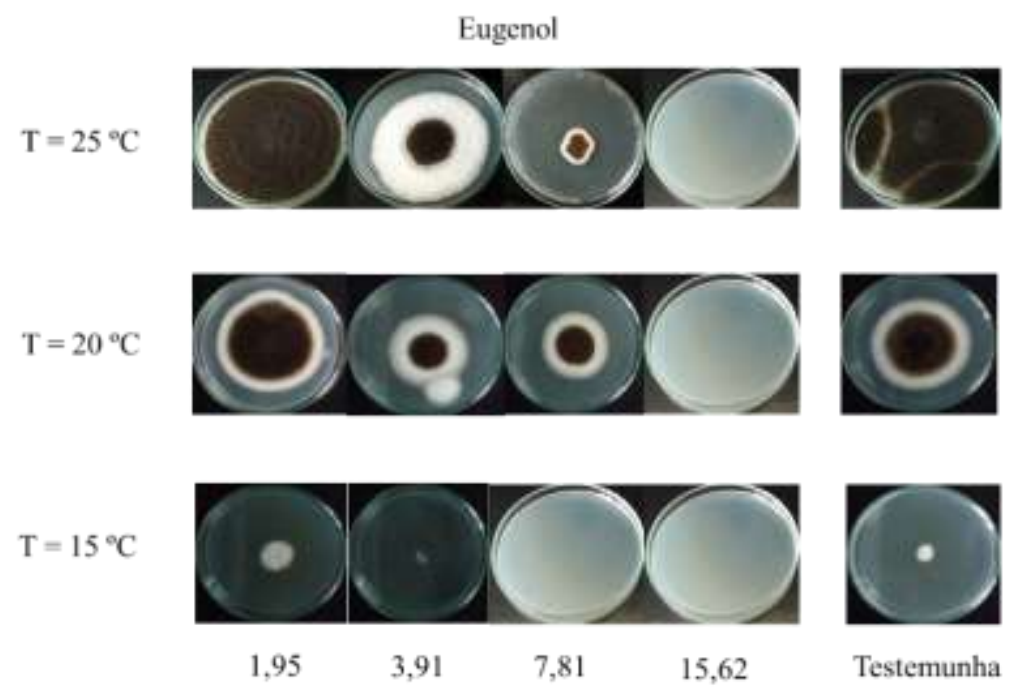

Fonte: Autores (2018).

Pode-se perceber o efeito da temperatura ao comparar o halo de crescimento formado para as testemunhas, bem como o efeito do composto, juntamente nas diferentes temperaturas entre as concentrações estudadas. Assim, nota-se que tanto a testemunha quanto os fungos analisados apresentaram desenvolvimento inferior na temperatura de $15^{\circ} \mathrm{C}$, quando comparados com as temperaturas de $20{ }^{\circ} \mathrm{C}$ e $25^{\circ} \mathrm{C}$. A temperatura de $15^{\circ} \mathrm{C}$ não propiciou o crescimento do fungo A. carbonarius, quando testado com o composto citral em nenhuma concentração e houve crescimento razoável para os demais compostos.

Os valores do diâmetro médio do crescimento micelial do fungos A. niger sobre os compostos analisados estão representados nas Tabelas 5, 6 e 7.

Tabela 5. Diâmetro médio do crescimento micelial do fungo Aspergillus niger sobre o composto carvacrol.

\begin{tabular}{|c|c|c|c|c|c|c|}
\hline \multirow{2}{*}{$\begin{array}{l}\text { Concentração } \\
\left(\mu \mathrm{L} \mathrm{mL}{ }^{-1}\right)\end{array}$} & \multicolumn{3}{|c|}{ Temperatura $\left({ }^{\circ} \mathrm{C}\right)$} & \multicolumn{3}{|c|}{ Inibição micelial (\%) } \\
\hline & 15 & 20 & 25 & 15 & 20 & 25 \\
\hline 1,95 & $4,033 \mathrm{Bc}$ & 7,383 Bb & $8,833 \mathrm{Aa}$ & 18,525 & 13,141 & 1,856 \\
\hline 3,91 & $3,783 \mathrm{Bc}$ & $7,150 \mathrm{Bb}$ & $9,000 \mathrm{Aa}$ & 23,576 & 15,882 & 0,000 \\
\hline 7,81 & $1,567 \mathrm{Cc}$ & $5,883 \mathrm{Cb}$ & $9,000 \mathrm{Aa}$ & 68,343 & 30,788 & 0,000 \\
\hline 15,62 & $0,000 \mathrm{Da}$ & $0,000 \mathrm{Da}$ & $0,000 \mathrm{Ba}$ & 100,000 & 100,000 & 100,000 \\
\hline Testemunha & $4,950 \mathrm{Ab}$ & $8,500 \mathrm{Aa}$ & $9,000 \mathrm{Aa}$ & 0,000 & 0,000 & 0,000 \\
\hline
\end{tabular}

Legenda: As médias seguidas pela mesma letra minúscula nas colunas e pela mesma letra maiúscula nas linhas não diferem entre si pelo Teste de Tukey, ao nível de 5\% de probabilidade. Fonte: Autores (2018). 
Tabela 6. Diâmetro médio do crescimento micelial do fungo Aspergillus niger sobre o composto citral.

\begin{tabular}{|c|c|c|c|c|c|c|}
\hline \multirow{2}{*}{$\begin{array}{l}\text { Concentração } \\
\left(\mu \mathrm{L} \mathrm{mL} \mathrm{L}^{-1}\right)\end{array}$} & \multicolumn{3}{|c|}{ Temperatura $\left({ }^{\circ} \mathrm{C}\right)$} & \multicolumn{3}{|c|}{ Inibição micelial (\%) } \\
\hline & 15 & 20 & 25 & 15 & 20 & 25 \\
\hline 1,95 & $4,500 \mathrm{Ab}$ & 7,883 Aa & $9,000 \mathrm{Aa}$ & 9,091 & 7,259 & 0,000 \\
\hline 3,91 & $5,300 \mathrm{Ab}$ & $6,500 \mathrm{Bb}$ & $9,000 \mathrm{Aa}$ & 0,000 & 23,529 & 0,000 \\
\hline 7,81 & $2,450 \mathrm{Bc}$ & $4,683 \mathrm{Cb}$ & $6,483 \mathrm{Ba}$ & 50,505 & 44,906 & 27,967 \\
\hline 15,62 & $0,000 \mathrm{Ca}$ & $0,000 \mathrm{Da}$ & $0,000 \mathrm{Ca}$ & 100,000 & 100,000 & 100,000 \\
\hline Testemunha & $4,950 \mathrm{Ab}$ & $8,500 \mathrm{Aa}$ & $9,000 \mathrm{Aa}$ & 0,000 & 0,000 & 0,000 \\
\hline
\end{tabular}

Legenda: As médias seguidas pela mesma letra minúscula nas colunas e pela mesma letra maiúscula nas linhas não diferem entre si pelo Teste de Tukey, ao nível de 5\% de probabilidade. Fonte: Autores (2018).

Tabela 7. Diâmetro médio do crescimento micelial do fungo Aspergillus niger sobre o composto eugenol.

\begin{tabular}{ccccccc}
\hline \multirow{2}{*}{$\begin{array}{c}\text { Concentração } \\
\left(\mu \mathrm{L} \mathrm{mL} \mathrm{mL}^{-1}\right)\end{array}$} & \multicolumn{3}{c}{ Temperatura $\left({ }^{\circ} \mathrm{C}\right)$} & \multicolumn{3}{c}{ Inibição micelial $(\%)$} \\
\cline { 2 - 7 } & 15 & 20 & 25 & 15 & 20 & 25 \\
\hline 1,95 & $3,967 \mathrm{Bc}$ & $7,783 \mathrm{Bb}$ & $9,000 \mathrm{Aa}$ & 19,858 & 8,435 & 0,000 \\
3,91 & $4,700 \mathrm{Ac}$ & $6,867 \mathrm{Cb}$ & $9,000 \mathrm{Aa}$ & 5,050 & 19,212 & 0,000 \\
7,81 & $2,883 \mathrm{Cc}$ & $6,250 \mathrm{Db}$ & $9,000 \mathrm{Aa}$ & 41,758 & 26,471 & 0,000 \\
15,62 & $0,000 \mathrm{Db}$ & $0,000 \mathrm{~Eb}$ & $1,217 \mathrm{Ba}$ & 100,000 & 100,000 & 86,478 \\
Testemunha & $4,950 \mathrm{Ab}$ & $8,500 \mathrm{Aa}$ & $9,000 \mathrm{Aa}$ & 0,000 & 0,000 & 0,000 \\
\hline
\end{tabular}

Legenda: As médias seguidas pela mesma letra minúscula nas colunas e pela mesma letra maiúscula nas linhas não diferem entre si pelo Teste de Tukey, ao nível de 5\% de probabilidade. Fonte: Autores (2018).

Ambos os compostos, carvacrol e citral, apresentaram inibição total do crescimento micelial de A. niger a partir da concentração de $15,625 \mu \mathrm{L} \mathrm{mL} \mathrm{L}^{-1}$, nas temperaturas analisadas, uma concentração acima daquela realizada no teste preliminar para CMI. Pelo teste preliminar para determinar a CMI, o eugenol apresentou uma CMI de 7,81 $\mu \mathrm{L}^{-1}$; entretanto mesmo em uma concentração acima dessa ocorreu crescimento micelial na temperatura de $25^{\circ} \mathrm{C}$. Diante dos valores do diâmetro médio das testemunhas e dos compostos nas diferentes concentrações, observa-se que o fungo A. niger foi um pouco mais resistente aos efeitos da temperatura, quando comparado com A. carbonarius, mesmo que apresente alterações significativas. Da mesma forma que A. carbonarius, o fungo A. niger sofreu influência da temperatura em relação ao crescimento micelial, sendo a temperatura de $15^{\circ} \mathrm{C}$ menos favorável ao seu desenvolvimento do que as temperaturas de $20{ }^{\circ} \mathrm{C}$ e $25^{\circ} \mathrm{C}$.

As Figuras 5, 6 e 7 mostram a inibição do crescimento micelial do fungo A. niger pelos compostos carvacrol, citral e eugenol, respectivamente, nas concentrações de 1,95 a $15,62 \mu \mathrm{L} \mathrm{mL}^{-1}$. 
Figura 5. Inibição do crescimento micelial de Aspergillus niger pelo composto carvacrol, nas temperaturas de 25,20 e $15{ }^{\circ} \mathrm{C}$. Carvacrol

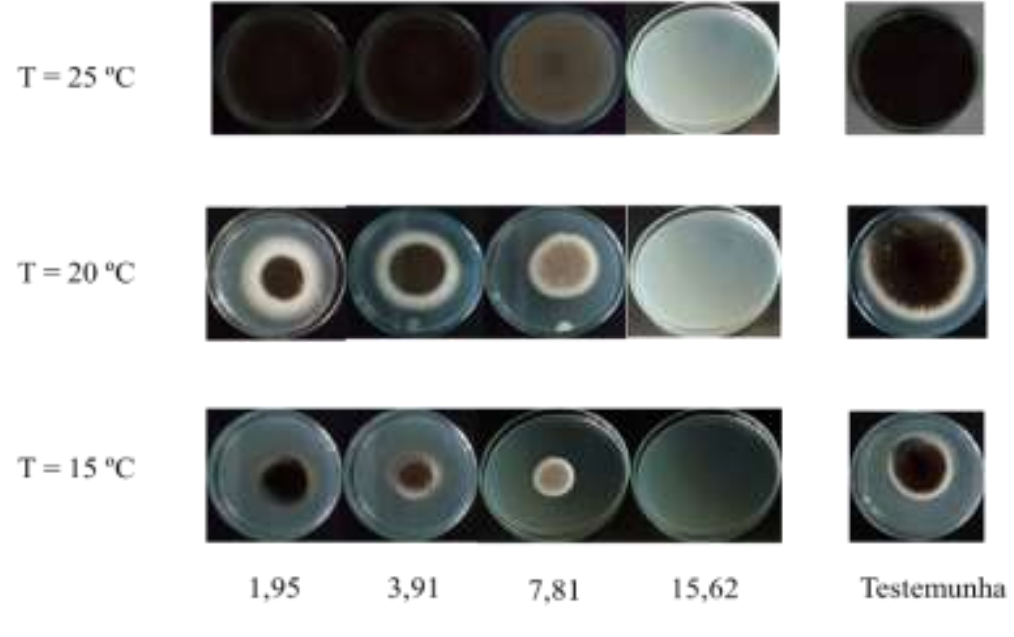

Fonte: Autores (2018).

Figura 6. Inibição do crescimento micelial de Aspergillus niger pelo composto citral, nas temperaturas de 25,20 e $15^{\circ} \mathrm{C}$.

Citral

$\mathrm{T}=25^{\circ} \mathrm{C}$
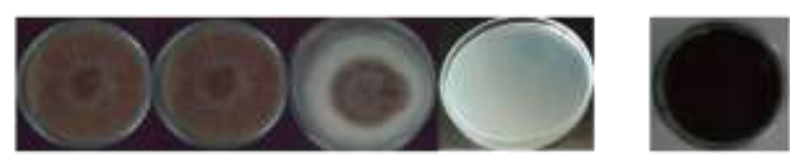

$\mathrm{T}=20^{\circ} \mathrm{C}$
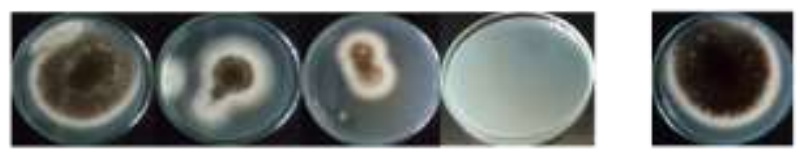

$\mathrm{T}=15^{\circ} \mathrm{C}$
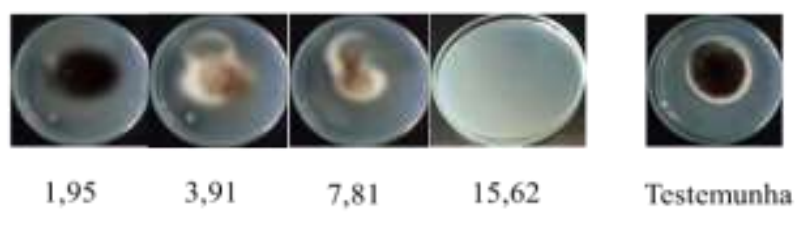

Fonte: Autores (2018). 
Figura 7. Inibição do crescimento micelial de Aspergillus niger pelo composto eugenol, nas temperaturas de 25,20 e $15^{\circ} \mathrm{C}$.

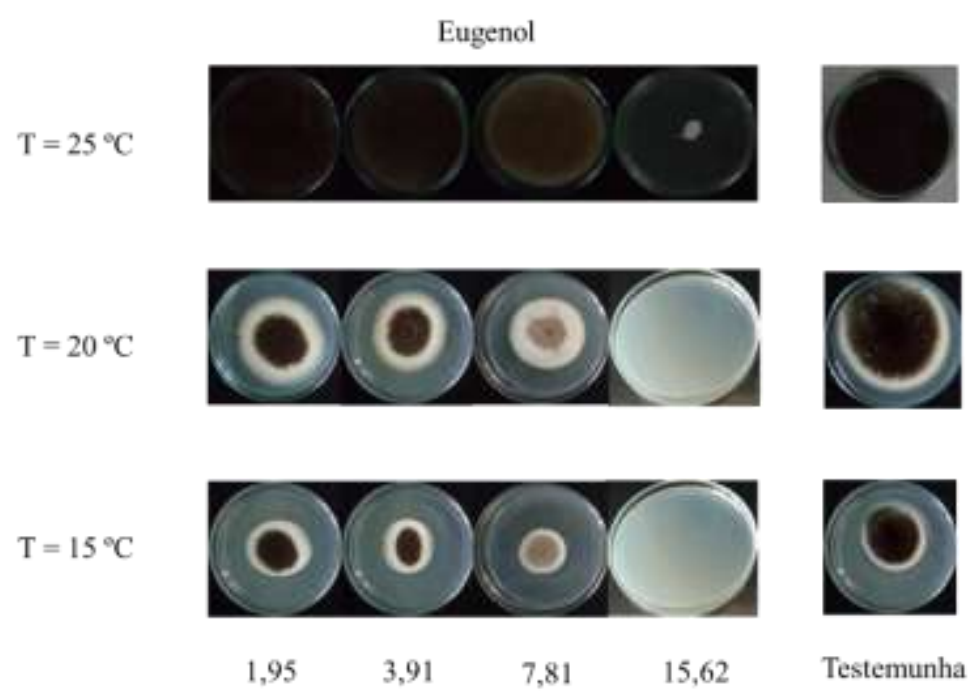

Fonte: Autores (2018).

Além da influência significativa da temperatura sobre o crescimento micelial, ressalta-se a coloração do micélio, apresentando-se mais claro nas concentrações maiores, revelando, assim, uma interação do composto com o fungo, mesmo que tenha ocorrido o crescimento micelial. A perda da pigmentação não foi observada nas testemunhas, confirmando a interação do composto com o fungo e não o efeito da variação da temperatura.

Pelos dados descritos, observou-se que os compostos agiram conforme o esperado para ambos os fungos testados, visto que houve aumento na atividade de inibição do crescimento micelial com o aumento da concentração, apresentando uma relação dose-dependente sobre a atividade antifúngica.

Os dados revelam que os efeitos da temperatura influenciaram diretamente a atividade antifúngica dos fungos $A$. carbonarius e A. niger, atuando no crescimento micelial e, consequentemente, na síntese de ocratoxina. Os fungos produtores de micotoxinas estão correlacionados com a temperatura, uma vez que é evidenciado na literatura que houve baixa ou nenhuma produção em temperaturas refrigeradas, produção intermediária em torno de $12{ }^{\circ} \mathrm{C}$ e produção ótima entre 20 e $25^{\circ} \mathrm{C}(\mathrm{Hymery}$ et al., 2014).

O controle de temperatura é um dos métodos mais utilizados de manipulação da ecologia microbiana dos alimentos. Pode ser usado para inibir o crescimento de organismos patogênicos, inativar ou matar micro-organismos indesejados, ou otimizar o crescimento ou o metabolismo dos micro-organismos nas fermentações. As células fúngicas são compostas por enzimas e a atividade funcional dessas enzimas são dependentes de sua forma ou conformação. A temperatura afeta as ligações químicas na molécula e, se a temperatura sofre muita variação, a conformação fica distorcida a ponto de a enzima não estar mais ativada cataliticamente. Essa variação de temperatura pode resultar na desnaturação da proteína, que pode ocorrer tanto quando a temperatura está muito alta ou quando a temperatura está muito baixa (Ross \& Nichols, 2014).

Os micro-organismos, em particular os fungos, são conhecidos por produzir metabólitos secundários com propriedades antimicrobianas como mecanismo de defesa e também compostos com alta toxicidade, como as micotoxinas, sendo influenciados pelo efeito da temperatura (Yogabaanu et al., 2017). Pesquisas de Paterson e Lima (2011) reportaram as condições que favorecem a produção de ocratoxina A (micotoxinas produzidas por A. carbonarius e A. niger) em vinhos. Observaram que temperaturas elevadas, em torno de $30^{\circ} \mathrm{C}$, juntamente com o aumento da umidade, são fatores de risco, uma vez que acentuam a produção de ocratoxina OTA e que temperaturas inferiores a $21^{\circ} \mathrm{C}$ são mais seguras. 


\section{Conclusão}

Os compostos eugenol, carvacrol e citral pertencentes às classes dos fenilpropanoides, monoterpenos com carcterísticas fenólicas e monoterpenos oxigenados, respectivamente apresentaram maior atividade inibitória sobre os fungos filamentosos analisados. Verificou-se que esses compostos reduzem o crescimento micelial dos fungos A. niger e A. carbonarius, quando testados em diferentes temperaturas.

De modo geral, os compostos carvacrol, citral e eugenol mostraram-se eficientes sobre os fungos filamentosos $A$. carbonarius e A. niger, sendo promissores na busca por compostos naturais com potencial antimicrobiano. Além disso, o processo de estocagem dos alimentos, como grãos, frutas, cereais, entre outros, é favorecido em temperaturas mais baixas, pois essas são menos propícias ao desenvolvimento dos fungos e, consequentemente, à produção de micotoxinas. Nesse sentido, a pesquisa por compostos de origem natural, a fim de combater o crescimento de micro-organismos prejudiciais à saúde humana, é de extrema relevância.

\section{Agradecimentos}

Os autores agradecem à Universidade Federal de Lavras (UFLA), ao Conselho Nacional de Desenvolvimento Científico e Tecnológico (CNPq), à Coordenação de Aperfeiçoamento de Pessoal de Nível Superior (CAPES) e à Fundação de Amparo à Pesquisa do Estado de Minas Gerais (FAPEMIG).

\section{Referências}

Abbaszadeh, S., Sharifzadeh, A., Shokri, H., Khosravi, A. R, \& Abbaszadeh, A. (2014). Antifungal efficacy of thymol, carvacrol, eugenol and menthol as alternative agents to control the growth of food-relevant fungi. Journal de mycologie medicale, 24 (2), e51-e56. http://dx.doi.org/10.1016/j.mycmed.2014.01.063

Ahmad, A., Khan, A., Kumar, P., Bhatt, R. P, \& Manzoor, N. (2011). Antifungal activity of Coriaria nepalensis essential oil by disrupting ergosterol biosynthesis and membrane integrity against Candida. Levedura, 28 (8), 611-617. https://doi.org/10.1002/yea.1890

Andrade, M. A., Cardoso, M. D. G., Gomes, M. D. S., Azeredo, C. M. O. D., Batista, L. R., Soares, M. J., Rodrigues, L. M. A., \& Figueiredo, A. C. S. (2015). Biological activity of the essential oils from Cinnamodendron dinisii and Siparuna guianensis. Brazilian Journal of Microbiology, 46, 189-194. https://doi.org/10.1590/S1517-838246120130683

Bhatti, H. N., Khan, S. S., Khan, A., Rani, M., Ahmad, V. U., \& Choudhary, M. I. (2014). Biotransformation of monoterpenoids and their antimicrobial activities. Phytomedicine, 21(12), 1597-1626. https://dx.doi.org/10.1016/j.phymed.2014.05.011

Brasil. (2017). Vigilância sanitária. Antimicrobianos - Bases Teóricas e Uso Clínico. <http://www.anvisa.gov.br/servicosaude/controle/rede_rm/c ursos/rm_controle/opas_web/modulo1/conceitos.htm

Cristani, M., D'Arrigo, M., Mandalari, G., Castelli, F., Sarpietro, M. G., Micieli, D, Venuti, V., Bisignano, G., Saija, A., \& Trombetta, D. (2007). Interaction of four monoterpenes contained in essential oils with model membranes: implications for their antibacterial activity. Journal of agricultural and food chemistry, 55(15), 6300-6308. https://doi.org/10.1021/jf070094x

D'Amato, S., Serio, A., López, C. C., \& Paparella, A. (2018). Hydrosols: Biological activity and potential as antimicrobials for food applications. Food Control, 86, 126-137. https://doi.org/10.1016/j.foodcont.2017.10.030

Davies, C. R, Wohlgemuth, F., Young, T., Violet, J., Dickinson, M., Sanders, J. W., Vallieres, C., \& Avery, S. V (2021). Desafios e estratégias em evolução para o controle de fungos na cadeia de abastecimento alimentar. Fungal biology reviews, 36, 15-26. https://doi.org/10.1016/j.fbr.2021.01.003

Oliveira, K. G., Batista, E. A., da Silva Kraljic, P., da Matta, R. A., Batista, R. M., Lucas, V. A. S., \& Fernandes, S. H. (2020). Desenvolvimento de um fungicida natural à partir de piperina. Brazilian Journal of Development, 6 (7), 46433-46447. https://doi.org/10.34117/bjdv6n7-321

Ferreira, D. F. (2011). Sisvar: a computer statistical analysis system. Ciência e agrotecnologia, 35, 1039-1042.

Gomes, M. S., Cardoso, M. D. G., Soares, M. J., Batista, L. R., Machado, S. M., Andrade, M. A., Azeredo, C. M.O., Resende, J. M. V., \& Rodrigues, L. M. A. (2014). Use of essential oils of the genus Citrus as biocidal agents. http://dx.doi.org/10.4236/ajps.2014.53041

Hyldgaard, M., Mygind, T., \& Meyer, R. L. (2012). Essential oils in food preservation: mode of action, synergies, and interactions with food matrix components. Frontiers in microbiology, 3, 12. https://doi.org/10.3389/fmicb.2012.00012

Hymery, N., Vasseur, V., Coton, M., Mounier, J., Jany, J. L., Barbier, G., \& Coton, E. (2014). Filamentous fungi and mycotoxins in cheese: a review. Comprehensive Reviews in Food Science and Food Safety, 13 (4), 437-456. https://doi.org/10.1111/1541-4337.12069 
Hu, Y., Zhang, J., Kong, W., Zhao, G., \& Yang, M. (2017). Mechanisms of antifungal and anti-aflatoxigenic properties of essential oil derived from turmeric (Curcuma longa L.) on Aspergillus flavus. Food chemistry, 220, 1-8. https://doi.org/10.1016/j.foodchem.2016.09.179

Ketzer, F., Bemvenuti, A., Veiverberg, S., Dörr, M. G., \& Schmidt, M. E. (2020). Uso do extrato de Tabernaemontana catharinensis como fungicida alternativo para agricultura natural. Brazilian Journal of Development, 6 (7), 45050-45059. https://doi.org/10.34117/bjdv6n7-213

Leite, M. C. A., Bezerra, A. P. D. B., Sousa, J. P. D., Guerra, F. Q. S., \& Lima, E. D. O. (2014). Evaluation of antifungal activity and mechanism of action of citral against Candida albicans. Evidence-Based Complementary and Alternative Medicine, 2014. http://dx.doi.org/10.1155/2014/378280

Lagrouh, F., Dakka, N., \& Bakri, Y. (2017). The antifungal activity of Moroccan plants and the mechanism of action of secondary metabolites from plants. Journal de mycologie medicale, 27(3), 303-311. http://dx.doi.org/10.1016/j.mycmed.2017.04.008

Lemos, J. G., Stefanello, A., Bernardi, A. O., Garcia, M. V., Magrini, L. N., Cichoski, A. J., Wagner, R., \& Copetti, M. V. (2020). Antifungal efficacy of sanitizers and electrolyzed waters against toxigenic Aspergillus. Food Research International, 137, 109-451. https://doi.org/10.1016/j.foodres.2020.109451

Wink, N. Secondary Metabolites, the Role in Plant Diversification. Encyclopedia of Evolutionary Biology. 2016.

Oliveira, L. B. S., Batista, A. H. M., Fernandes, F. C., Sales, G. W. P., \& Nogueira, N. A. P. (2016). Atividade antifúngica e possível mecanismo de ação do óleo essencial de folhas de Ocimum gratissimum (Linn.) sobre espécies de Candida. Revista Brasileira de Plantas Medicinais, 18, 511-523. https://doi.org/10.1590/1983-084X/15_222

Paterson, R. R. M., \& Lima, N. (2011). Further mycotoxin effects from climate change. Food Research International, 44 (9), 2555-2566. https://doi.org/10.1016/j.foodres.2011.05.038

Pisoschi, A. M., Pop, A., Georgescu, C., Turcuş, V., Olah, N. K., \& Mathe, E. (2018). An overview of natural antimicrobials role in food. European Journal of Medicinal Chemistry, 143, 922-935. https://doi.org/10.1016/j.ejmech.2017.11.095

Ross, T., Nichols, D. S. (2014) Influence of Temperature. In: Encyclopedia of Food Microbiology. University of Tasmania, Hobart, TAS, Australia, 602-609.

Silva, F., Ferreira, S., Duarte, A., Mendonca, D. I., \& Domingues, F. C. (2011). Antifungal activity of Coriandrum sativum essential oil, its mode of action against Candida species and potential synergism with amphotericin B. Phytomedicine, 19 (1), 42-47. https://doi.org/10.1016/j.phymed.2011.06.033

Sun, J., Deng, Z., \& Yan, A. (2014). Bacterial multidrug efflux pumps: mechanisms, physiology and pharmacological exploitations. Biochemical and biophysical research communications, 453 (2), 254-267. https://doi.org/10.1016/j.bbrc.2014.05.090

Tian, J., Ban, X., Zeng, H., He, J., Chen, Y., \& Wang, Y. (2012). The mechanism of antifungal action of essential oil from dill (Anethum graveolens L.) on Aspergillus flavus. PloS one, 7 (1), e30147. https://doi.org/10.1371/journal.pone.0030147

Ultee, A., Bennik, M. H. J., \& Moezelaar, R. J. A. E. M. (2002). The phenolic hydroxyl group of carvacrol is essential for action against the food-borne pathogen Bacillus cereus. Applied and environmental microbiology, 68(4), 1561-1568. https://doi.org/10.1128/AEM.68.4.1561-1568.2002

Vieira, P. R., de Morais, S. M., Bezerra, F. H., Ferreira, P. A. T., Oliveira, Í. R., \& Silva, M. G. V. (2014). Chemical composition and antifungal activity of essential oils from Ocimum species. Industrial Crops and Products, 55, 267-271. https://doi.org/10.1016/j.indcrop.2014.02.032

Yogabaanu, U., Weber, J. F. F., Convey, P., Rizman-Idid, M., \& Alias, S. A. (2017). Antimicrobial properties and the influence of temperature on secondary metabolite production in cold environment soil fungi. Polar Science, 14, 60-67. https://doi.org/10.1016/j.polar.2017.09.005

Zore, G. B., Thakre, A. D., Jadhav, S., \& Karuppayil, S. M. (2011). Terpenoids inhibit Candida albicans growth by affecting membrane integrity and arrest of cell cycle. Phytomedicine, 18(13), 1181-1190. https://doi.org/10.1016/j.phymed.2011.03.008

Wang, Y., Zeng, X., Zhou, Z., Xing, K., Tessema, A., Zeng, H., \& Tian, J. (2015). Inhibitory effect of nerol against Aspergillus niger on grapes through a membrane lesion mechanism. Food Control, 55, 54-61. https://doi.org/10.1016/j.foodcont.2015.02.029 